\title{
Modeling the Influence of the Composition of Refractory Elements on the Heat Resistance of Nickel Alloys by a Deep Learning Artificial Neural Network
}

\author{
Dmitry TARASOV ${ }^{1}$, Oleg Milder ${ }^{1}$, and Andrei Tiagunov ${ }^{1}$ \\ ${ }^{1}$ Ural Federal University named after the first President of Russia B N Yeltsin
}

December 27, 2020

\begin{abstract}
Nickel alloys are widely used in the production of gas turbine parts. The alloys show resistance to mechanical and chemical degradation under severe long-term stress and high temperatures. One of the major mechanical properties of the alloys is the high-temperature rupture strength, which is measured after a specimen is heated to a certain temperature and held for a certain time considering deformation. Determining the influence of certain elements on the properties of an alloy is a complex scientific and engineering problem that affects the time and cost of developing new materials. Simulation is a great chance to cut costs. In this paper, we predict a high-temperature strength based on the composition of refractory elements in alloys using a deep learning artificial neural network. We build the model based on prior knowledge of the composition of the alloys, information on the role of alloying elements, type of crystallization, test temperature and time, and the tensile strength. Successful simulation results show the applicability of this method in practice.
\end{abstract}

\section{Hosted file}

DLANN_alloys-final.pdf available at https://authorea.com/users/360082/articles/500875modeling-the-influence-of-the-composition-of-refractory-elements-on-the-heat-resistanceof-nickel-alloys-by-a-deep-learning-artificial-neural-network

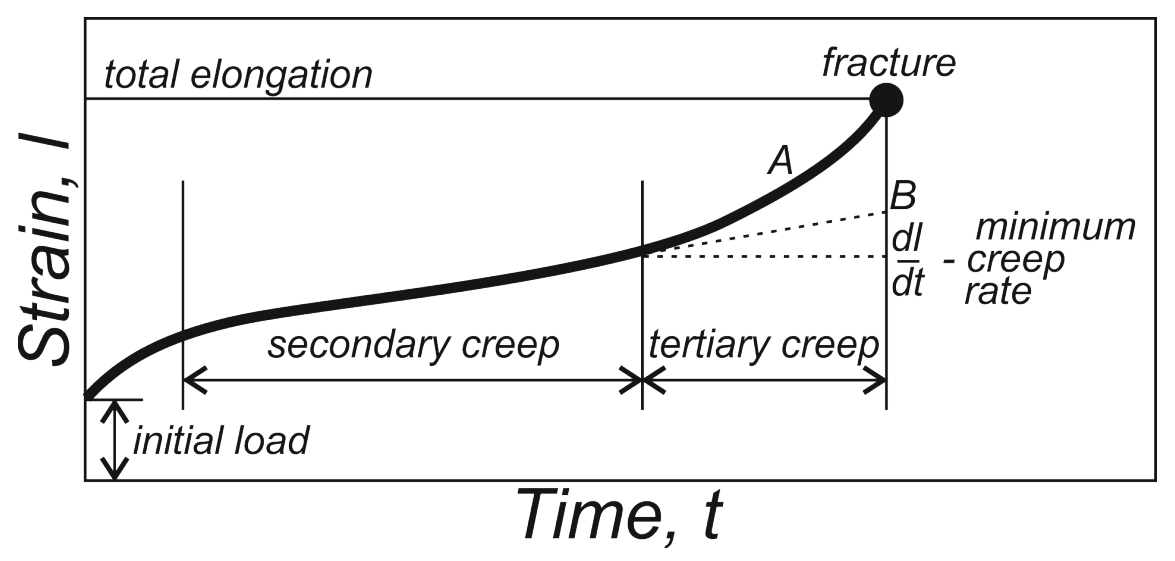



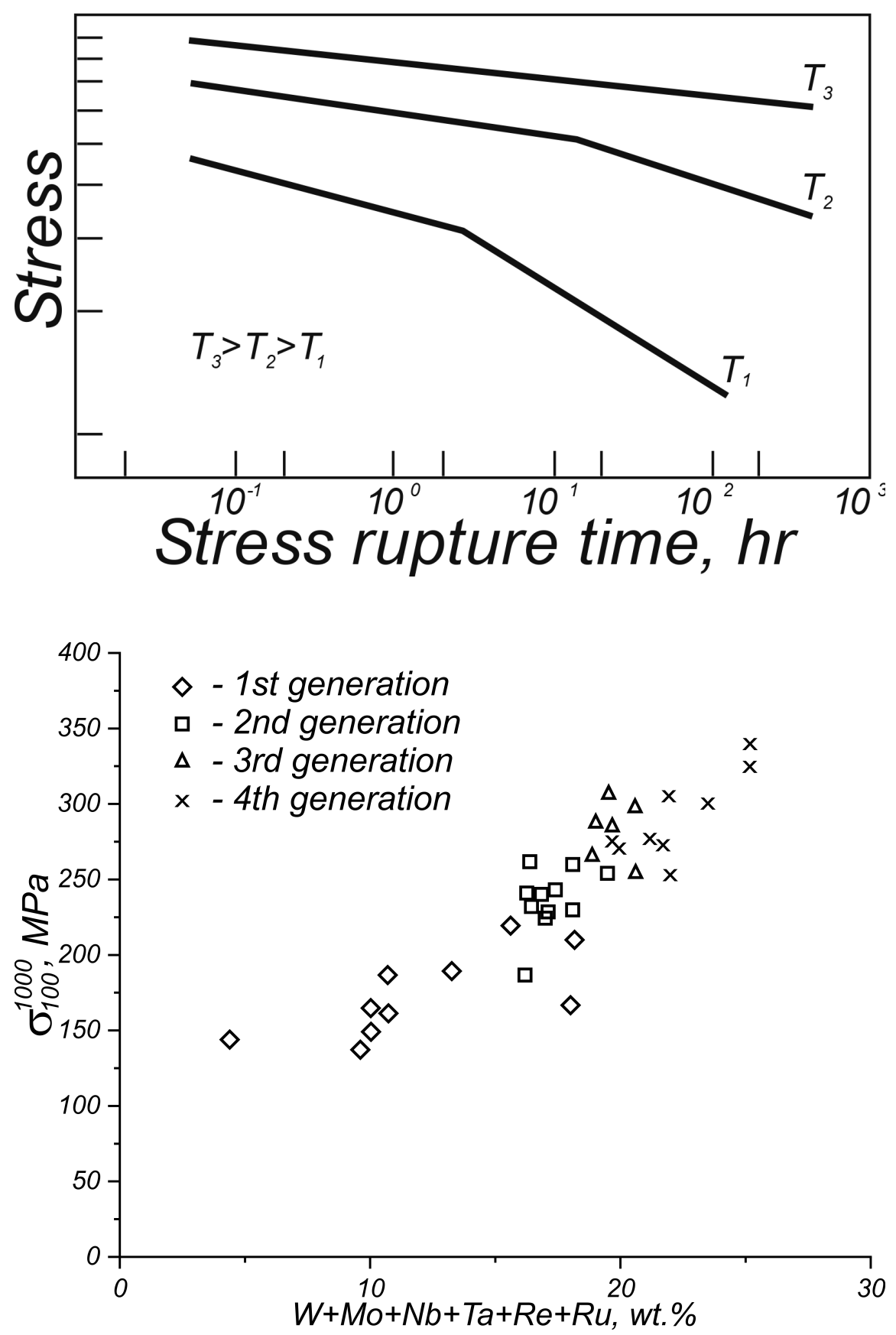

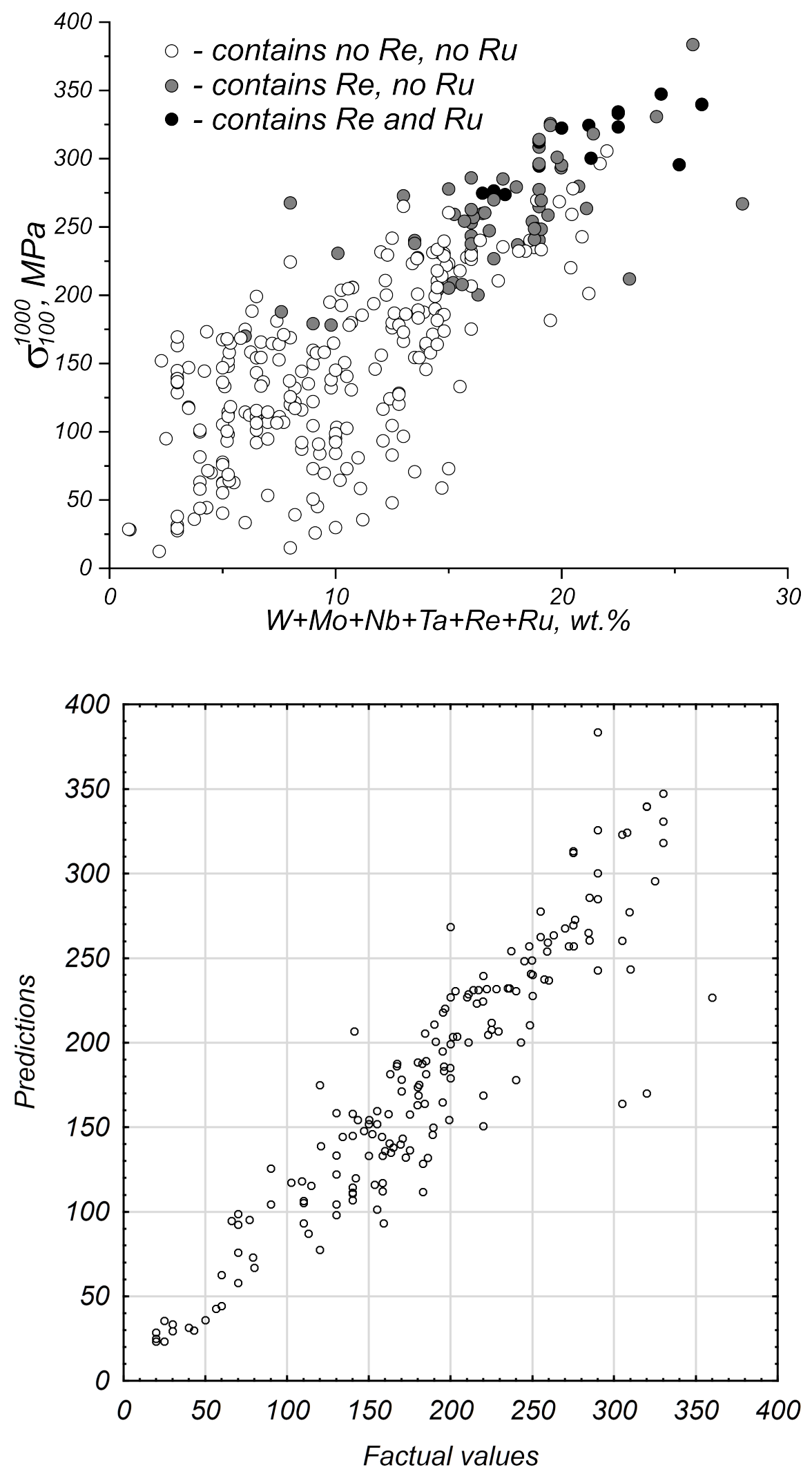


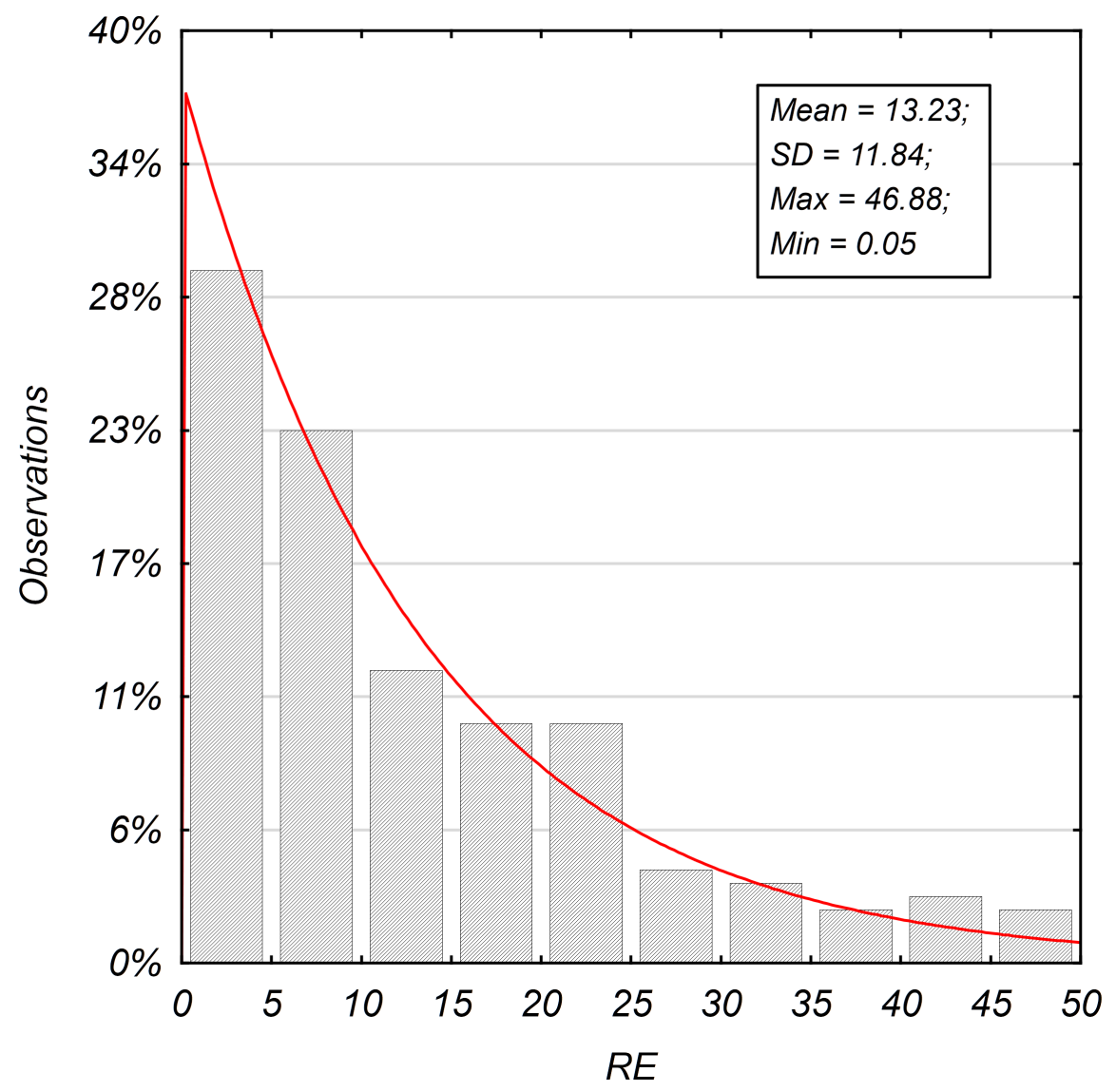

